\section{Pacific Northwest}

National Laboratory

Operated by Battelle for the

U.S. Department of Energy

\title{
Broadly Tunable External Cavity Quantum Cascade Laser Development
}

\author{
M. C. Phillips \\ T. L. Myers \\ M. S. Taubman
}

December 2007

Prepared for the U.S. Department of Energy under Contract DE-AC05-76RL01830 


\title{
DISCLAIMER
}

This report was prepared as an account of work sponsored by an agency of the United States Government. Neither the United States Government nor any agency thereof, nor Battelle Memorial Institute, nor any of their employees, makes any warranty, express or implied, or assumes any legal liability or responsibility for the accuracy, completeness, or usefulness of any information, apparatus, product, or process disclosed, or represents that its use would not infringe privately owned rights. Reference herein to any specific commercial product, process, or service by trade name, trademark, manufacturer, or otherwise does not necessarily constitute or imply its endorsement, recommendation, or favoring by the United States Government or any agency thereof, or Battelle Memorial Institute. The views and opinions of authors expressed herein do not necessarily state or reflect those of the United States Government or any agency thereof.

\author{
PACIFIC NORTHWEST NATIONAL LABORATORY \\ operated by \\ BATTELLE \\ for the \\ UNITED STATES DEPARTMENT OF ENERGY
}

under Contract DE-AC05-76RL01830

Printed in the United States of America
Available to DOE and DOE contractors from the Office of Scientific and Technical Information,
P.O. Box 62, Oak Ridge, TN 37831-0062;
ph: (865) 576-8401
fax: (865) 576-5728
email: reports@adonis.osti.gov

\footnotetext{
Available to the public from the National Technical Information Service, U.S. Department of Commerce, 5285 Port Royal Rd., Springfield, VA 22161 ph: (800) 553-6847 fax: (703) 605-6900

email: orders@ntis.fedworld.gov

online ordering: http://www.ntis.gov/ordering.htm
} 


\title{
Broadly Tunable External Cavity Quantum Cascade Laser Development
}

\author{
M. C. Phillips \\ T. L. Myers \\ M. S. Taubman
}

December 2007

Prepared for

the U.S. Department of Energy under Contract DE-AC05-76RL01830

Pacific Northwest National Laboratory

Richland, Washington 99352 


\section{Summary}

Pacific Northwest National Laboratory's (PNNL) Infrared Technology for Advanced Sensors (ITAS) project (PL05-OP211I-PD07) is focused on the development of a new generation of standoff and in-situ chemical sensors. Specific goals include high sensitivity detection of trace gases, high selectivity for interferent rejection, the ability to detect multiple species, and the successful field deployment of a sensor platform. The ITAS project uses laser absorption spectroscopy to accomplish these goals, utilizing the mid-infrared (MIR) spectral region from 5-25 $\mu \mathrm{m}$. The advantages of MIR spectroscopy are well-known; however, until recent years the lack of a compact, reliable, high-power laser source has hindered development of practical and fieldable MIR-based sensors.

The Laser Development Task of the ITAS project concentrates on developing the mid-infrared laser technology for these sensors. In particular, we are using quantum cascade (QC) lasers to provide highpower MIR sources, which are robust, reliable, and capable of operating without cryogenic cooling. Improvements in the growth and fabrication of QC lasers have continued to increase the performance of the devices, leading to corresponding enhancements in MIR spectroscopy and sensing.

To expand the versatility of MIR sensors, we have been working to develop broadly tunable external cavity quantum cascade lasers (ECQCLs). The ECQCL is capable of tuning over greater than $50 \mathrm{~cm}^{-1}$, and therefore provides the capability to detect multiple analytes simultaneously, or to detect molecules with broad absorption features. In FY05, PNNL developed an ECQCL using a room-temperature pulsed QC laser operated at a low duty cycle to evaluate the system architecture. In FY06 PNNL demonstrated higher power ECQCL systems which operated at room-temperature with high duty cycle pulses or in continuous-wave mode. These systems performed well for high-resolution spectroscopic applications, and were designed as replacements for DFB devices.

For this year, we continued to build on the technology developed in previous years by constructing an ECQCL system to target spectroscopy of molecules with broad absorption features. As part of the ECQCL characterization, we demonstrated high-sensitivity detection of various molecules with broad absorption features using two sensing techniques: photoacoustic spectroscopy and Herriott cell spectroscopy. In addition, the ECQCL system was capable of resolving the atmospherically-broadened absorption features of simple molecules. As a result, this ECQCL system represents a highly versatile laser source for MIR spectroscopy and sensing of a wide range of gas-phase molecules at atmospheric pressure. 


\section{Contents}

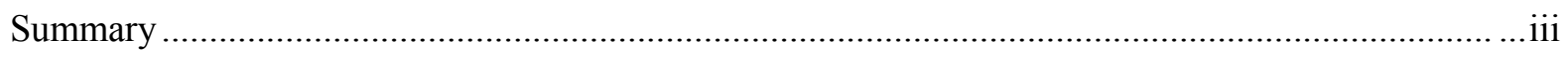

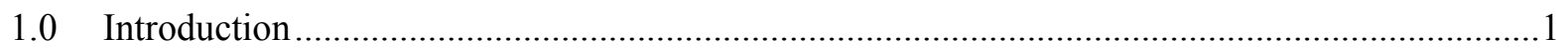

2.0 Broadly Tunable ECQCL Design and Characterization ..........................................................2

3.0 Photoacoustic Spectroscopy of Broad Absorption Features .................................................

4.0 Herriott Cell Spectroscopy of Broad Absorption Features ................................................. 10

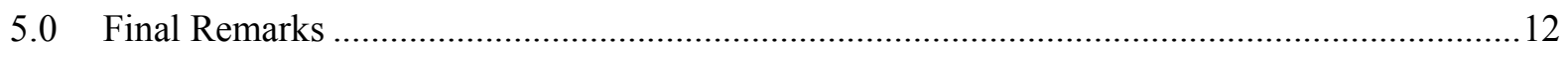

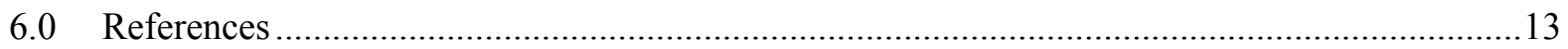




\section{Figures}

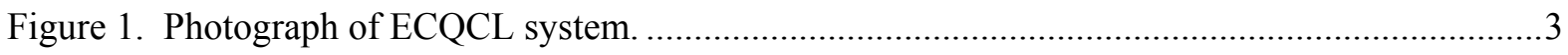

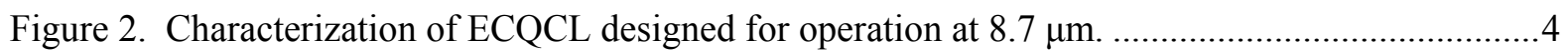

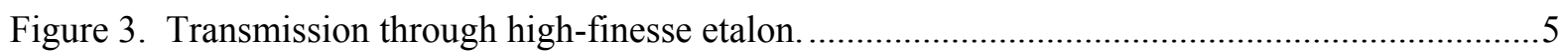

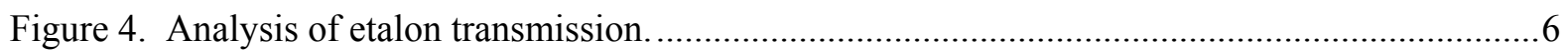

Figure 5. Modified pulse shape for increased tuning range. ...................................................

Figure 6. Increased tuning range of $8.7 \mu \mathrm{m}$ ECQCL with modified pulse shape. ............................... 7

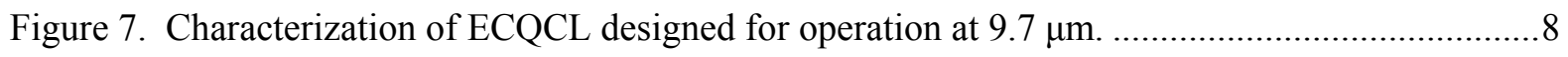

Figure 8. Photographs of quartz tuning forks (QTFs) used as photoacoustic transducers................... 9

Figure 9. Measurement of broad absorption features using QTF photoacoustic spectroscopy............9

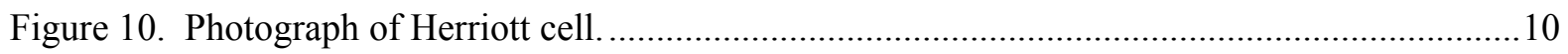

Figure 11. Measurement of Freon-125 absorption spectrum using ECQCL and Herriott cell............11

Figure 12. Measurement of water vapor absorption spectrum using ECQCL and Herriott cell..........12 


\subsection{Introduction}

The primary goal of the ECQCL development work this year was designing, characterizing, and testing a laser system to be used for sensing of molecules with broad absorption features. As grown in a FabryPerot (FP) device, a QC laser is not wavelength tunable and has limited use for spectroscopy. Additional processing to create a distributed feedback (DFB) device provides tuning over a limited range by varying the device current $\left(\sim 2 \mathrm{~cm}^{-1}\right.$ range) or temperature $\left(\sim 10 \mathrm{~cm}^{-1}\right.$ range). The DFB device is ideal for highresolution MIR spectroscopy of the narrow absorption features of simple gas-phase molecules. However, a single DFB device can usually target only one or a few target analytes. Furthermore, the tuning range is insufficient for reliable detection of molecules with broad absorption features.

An ECQCL using a typical QC laser device is able to tune over a range greater than $50 \mathrm{~cm}^{-1}$, and even larger tuning ranges are possible with specially engineered QC laser devices [1]. The spectral resolution required depends on the particular absorption spectrum of a given molecule. While solids and liquids typically have only broad features, many gas-phase molecules have a mixed absorption spectrum, containing both broad and narrow features. For maximum versatility, the ECQCL should have high enough spectral resolution to detect these narrow features. Because gas-phase molecules at atmospheric pressures do not usually have features narrower than $\sim 0.1 \mathrm{~cm}^{-1}$, this represents a good target resolution for the ECQCL system.

The ECQCL developed in FY06 was designed to tune over a small range $\left(\sim 0.1 \mathrm{~cm}^{-1}\right)$, and was used for high-resolution spectroscopy. However, the tuning mechanism was not capable of continuously scanning across the full tuning range of the ECQCL. Also, to accomplish the high-resolution tuning, the laser was operated in $\mathrm{CW}$ mode. Although CW QC lasers are becoming more readily available, their performance is often not optimal. We have found that in an ECQCL system, a QC laser can often provide both higher average power and a greater tuning range when pulsed at a high duty cycle instead of being operated CW. Furthermore, operating the laser in pulsed mode at a high duty cycle is well-suited for the use of lock-in detection for reducing detection noise and increasing sensitivity. The drawback to running the laser pulsed is the presence of thermally-induced wavelength chirp during the pulse. This wavelength chirp broadens the average linewidth of the ECQCL, and can lead to decreased scan resolution.

The difficulties in designing a tuning mechanism for an ECQCL arise because it is a coupled cavity laser system. One cavity is formed from the facets of the QC laser chip, leading to Fabry-Perot (FP) modes. The second cavity is formed by the external optics used for wavelength tuning, leading to external cavity (EC) modes. The cavity modes must be accounted for when tuning the ECQCL; otherwise, they lead to discrete (and often unpredictable) jumps in frequency, termed mode-hops. The spacing of the FP modes is relatively large in frequency, typically $\sim 0.5 \mathrm{~cm}^{-1}$, and the frequency jumps of this magnitude arising from FP mode-hops are undesirable for all but very low-resolution spectroscopy. Fortunately, the FP mode-hops are easy to eliminate by applying an antireflective (AR) coating to one facet of the QC laser chip. The EC modes depend on the length of the external cavity, and are more closely spaced than the FP modes. Eliminating the EC mode-hops entirely over the full tuning range of the ECQCL is very difficult, and requires precise and complex engineering of the tuning mechanism to control the cavity length. However, as the external cavity length is increased, the EC mode spacing is reduced. If high-resolution continuous tuning is not required, at some point the EC mode spacing becomes small enough that mode- 
hops become acceptable. We have determined that for the spectral features of interest, the presence of EC mode-hops is tolerable.

In Section 2 of this report, we first describe the modifications to the ECQCL design and the characterization of two versions designed for different wavelength ranges. The first version was designed for operation near $8.7 \mu \mathrm{m}$, and had a tuning range of up to $65 \mathrm{~cm}^{-1}$, with an average output power of 5 $\mathrm{mW}$ in the center of the tuning range. The second version was designed for operation near $9.7 \mu \mathrm{m}$, and had a tuning range of $110 \mathrm{~cm}^{-1}$, with an average power greater than $10 \mathrm{~mW}$. In Section 3, we present measurement of broad absorption features using the ECQCL in combination with a photoacoustic spectroscopy technique. In Section 4, we present results from measurement of broad absorption features using the ECQCL with a Herriott cell spectrometer. Despite the pulsed operation and the presence of EC mode-hops, we were able to demonstrate measurement of spectral features as narrow as $0.14 \mathrm{~cm}^{-1}$. As a result, the ECQCL system represents a versatile laser source for MIR spectroscopy and sensing of both complex molecules with broad absorption features, as well as simple molecules with atmospherically broadened absorption features.

\subsection{Broadly Tunable ECQCL Design and Characterization}

Figure 1 shows a photograph of the ECQCL setup, which is similar to previous versions developed under this project, based on the Littman-Metcalf external cavity design [2]. The QC laser was held at $15^{\circ} \mathrm{C}$ by a thermoelectric cooler (TEC). The laser output was collimated by a 0.5 " diameter custom germanium aspheric lens with $\mathrm{NA}=0.8$. The first $\mathrm{QC}$ laser device $(\mathrm{FQ8}-\mathrm{M} 446 \mathrm{~J})$ was obtained from Maxion Technologies and was used for experiments reported in FY2006. It was designed for room-temperature quasi-CW operation at a wavelength of $8.7 \mu \mathrm{m}$. The QC laser was provided with a high-reflection coating on the back facet and an antireflection coating on the front facet with an estimated reflectivity of $1 \%$. Custom electronics were used to drive the QC laser with pulses of 1.9 A peak current and $8 \mu \mathrm{s}$ duration. These conditions operated the laser near its maximum average power for pulse frequencies near $32 \mathrm{kHz}$. The pulse frequency was chosen for the photoacoustic spectroscopy measurements described in Section 3. 


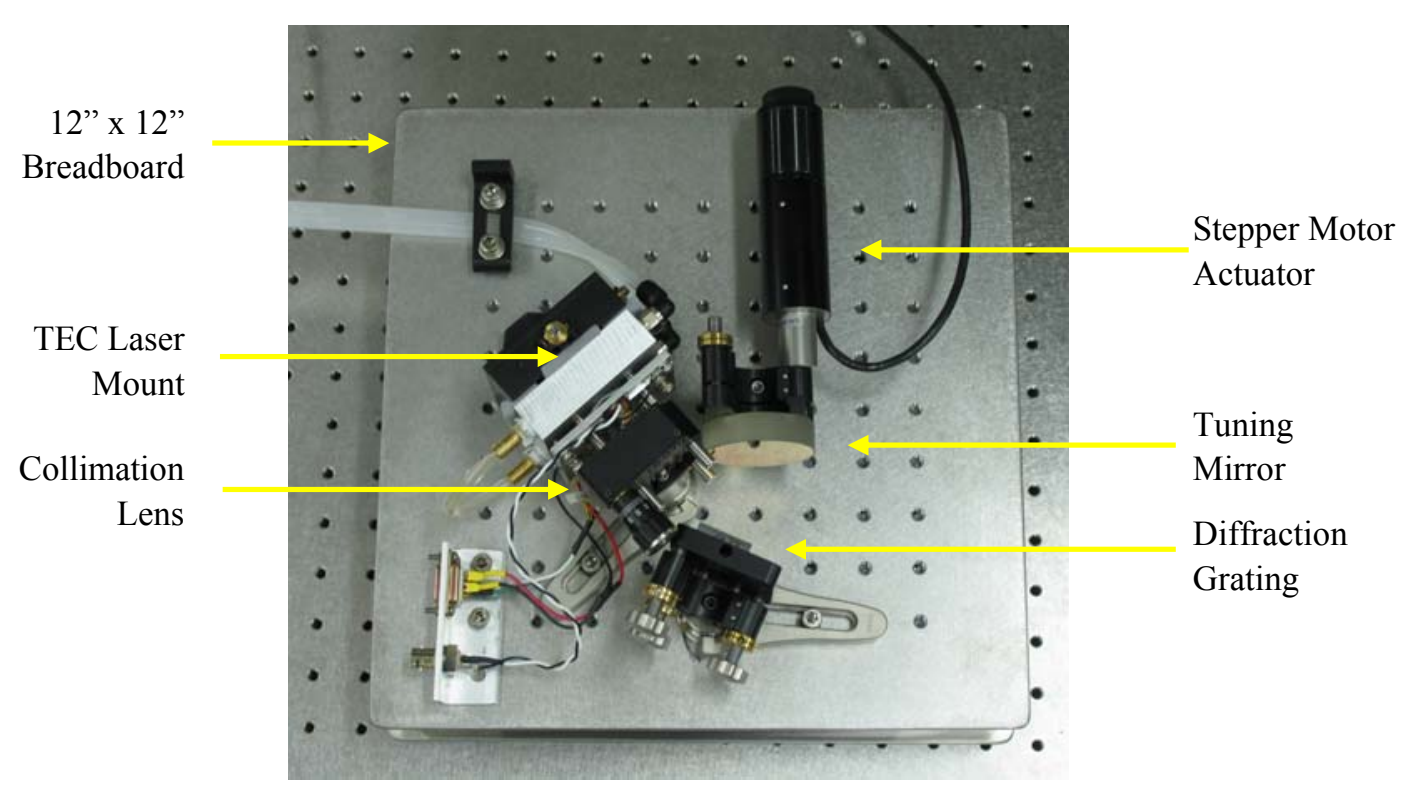

Figure 1. Photograph of ECQCL system.

In the Littman-Metcalf external cavity design, the collimated laser beam is directed to a diffraction grating. The first-order diffraction beam is then directed to a tuning mirror, whose angle determines the laser wavelength selected for optical feedback. The zeroth-order reflection from the diffraction grating provides the output beam for the laser. The previous design used a diffraction grating with 150 grooves $/ \mathrm{mm}$ blazed for $8 \mu \mathrm{m}$. This grating provided a very high diffraction efficiency of $\sim 90 \%$ over the laser tuning range centered at $8.7 \mu \mathrm{m}$ and was chosen to maximize the optical feedback to the laser. However, the high diffraction efficiency also acts to reduce the output power of the ECQCL. It was determined a lower efficiency grating could provide sufficient optical feedback, while increasing the output power. For the design used this year, a diffraction grating was selected with 150 grooves $/ \mathrm{mm}$ blazed for a wavelength of $6 \mu \mathrm{m}$, which had a diffraction efficiency of $\sim 70 \%$ at the laser wavelength.

Automated wavelength tuning was accomplished with the addition of a motorized actuator to control the angle of the tuning mirror. The motorized actuator (Thorlabs EAS503) used a stepper motor to extend a linear actuator over a maximum distance of $13 \mathrm{~mm}$ with a resolution of $40 \mathrm{~nm}$. The motion was controlled via commercial stepper motor drive electronics (Thorlabs BSC100) and a PC. The displacement of the linear actuator was used to change the angle of a commercial mirror mount. The total cavity length of the ECQCL was $10 \mathrm{~cm}$. 

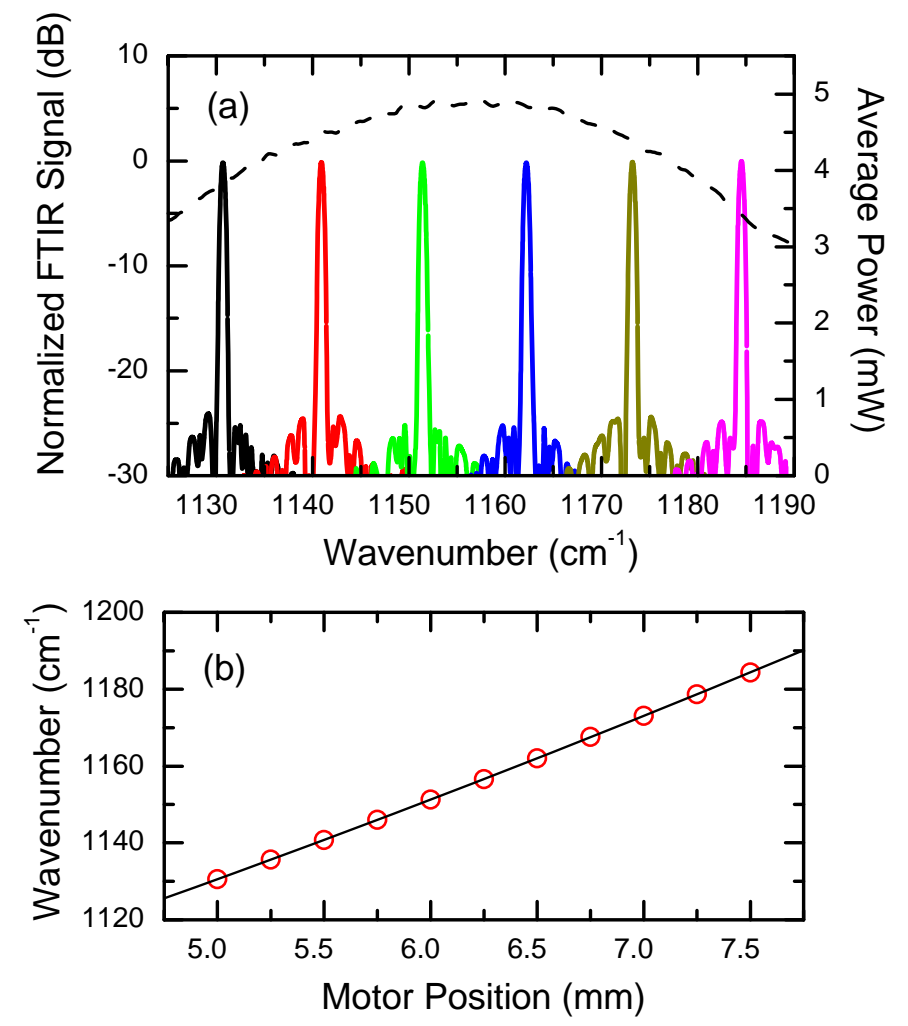

Figure 2. Characterization of ECQCL designed for operation at $8.7 \mu \mathrm{m}$. (a) Series of ECQCL output spectra (solid lines) recorded using an FTIR spectrometer. The ringing in the wings of the spectra is an artifact resulting from the limited spectral resolution of the FTIR and the apodization function used. The dashed line shows the average output power recorded using a thermopile detector. (b) Calibration of stepper motor position to wavenumber.

Figure 2(a) shows a series of ECQCL output spectra measured using a Fourier Transform Infrared (FTIR) spectrometer (Bruker OPAG 22) for different stepper motor positions. The ECQCL could be tuned from $1131-1185 \mathrm{~cm}^{-1}(8.44-8.84 \mu \mathrm{m})$ with a linewidth smaller than the $0.5 \mathrm{~cm}^{-1}$ resolution of the FTIR. Outside of this tuning range, the ECQCL output contained undesirable output from residual FP modes. The dashed line shows the average laser power measured using a thermopile detector. The spectra measured using the FTIR were used to calibrate the laser scan. The circles in Fig. 2(b) show the measured laser frequency versus stepper motor position. The solid line is a fit using a third-order polynomial, which approximates the trigonometric relationship between actuator displacement and wavenumber.

The ECQCL output undergoes a frequency chirp when the laser is pulsed and the resulting average linewidth over the duration of the pulse can be much larger than the instantaneous laser linewidth. The effective resolution of the ECQCL scan was characterized by measuring the transmission through a $6 \mathrm{~mm}$ air-spaced high-finesse etalon constructed from two high-reflectivity mirrors on $\mathrm{ZnSe}$ substrates. This etalon assembly had been previously used to measure the linewidth of a $\mathrm{CO}_{2}$ laser with a resolution better than $0.001 \mathrm{~cm}^{-1}$. The output from the ECQCL was directed through the etalon and detected with a liquid nitrogen cooled MCT detector. Figure 3(a) shows the detected signal as the ECQCL was scanned across its full tuning range, and Fig. 3(b) shows a smaller region of the tuning range. 


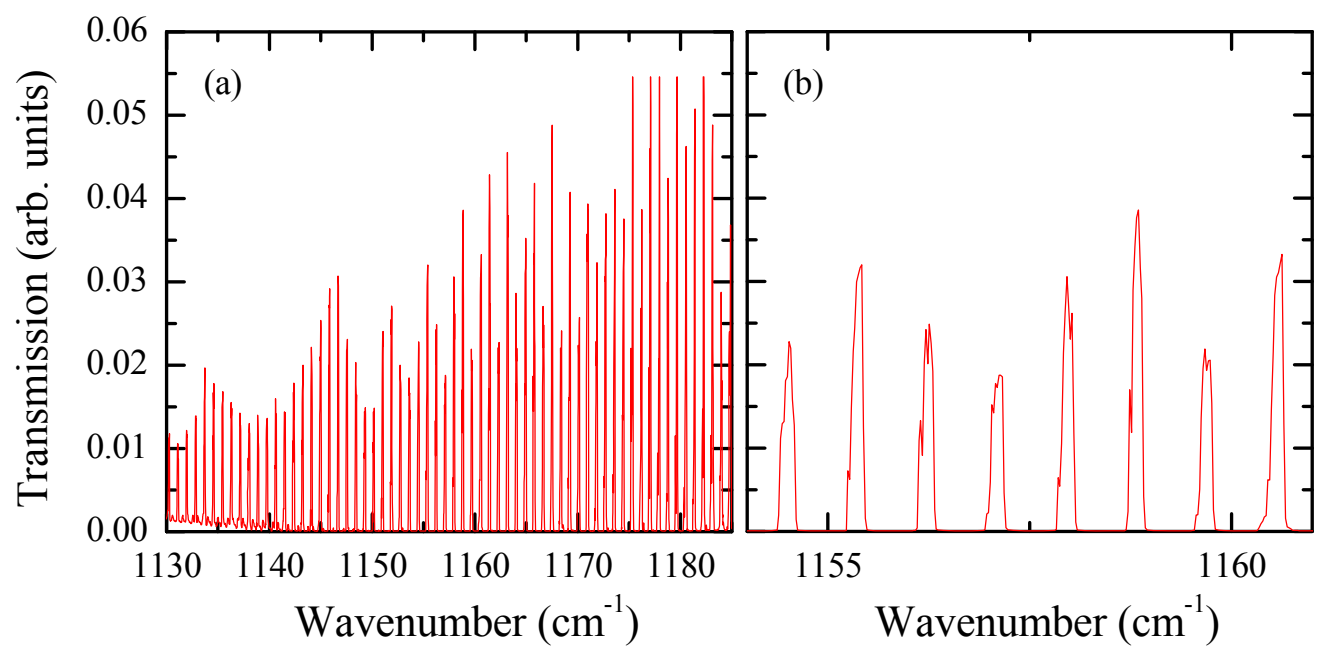

Figure 3. Transmission through high-finesse etalon. (a) Transmission over full tuning range of ECQCL. (b) Transmission over smaller range.

The etalon peaks were analyzed by measuring their center frequency based on the calibration shown in Fig. 2(b), and their full-width at half-maximum (FWHM). The measured positions of the etalon peaks are plotted in Fig. 4(a). The etalon peak positions were linear to within $0.03 \mathrm{~cm}^{-1}$, verifying the accuracy of the wavelength calibration and the linearity of the calibrated ECQCL scan. The FWHM for the etalon peaks is plotted in Fig. 4(b). The average width of the etalon peaks was $0.14 \mathrm{~cm}^{-1}$, with a maximum width measured of $0.19 \mathrm{~cm}^{-1}$. The etalon transmission measurement simulates the effect of measuring a spectral feature much narrower than the effective linewidth of the ECQCL. We use these values to define the effective scan resolution of the ECQCL system. The results from the etalon transmission show that ECQCL scan resolution is very usable despite the presence of mode-hops on the external cavity modes and wavelength chirp due to pulsed operation. 

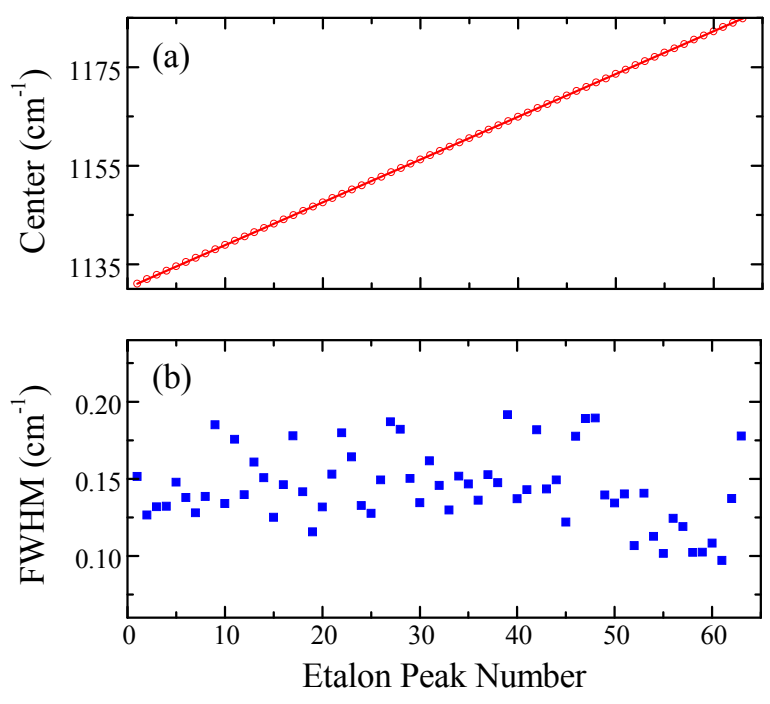

Figure 4. Analysis of etalon transmission. (a) Measured center position of etalon peaks (circles) and a linear fit (solid line). (b) Measured full-width at half maximum (FWHM) of etalon peaks.

Additional characterization of the ECQCL revealed that the tuning range of the ECQCL could be increased at the expense of output power by modifying the current pulse supplied to the QC laser. Instead of using a current pulse with sharp edges, we used a pulse with a slower rising edge. Figure 5 shows a schematic of the new pulse shape. As current is first applied to the QC laser during a pulse, the output light is multi-mode until enough round-trips of the external cavity have occurred to provide sufficient feedback. The slow rising edge reduces the output power of the ECQCL at the start of the current pulse, and therefore reduces the total amount of multi-mode light during the output optical pulse. At the edges of the QC gain profile, where the round-trip gain is smaller, this reduction in multi-mode output was found to increase the usable tuning range of the ECQCL.

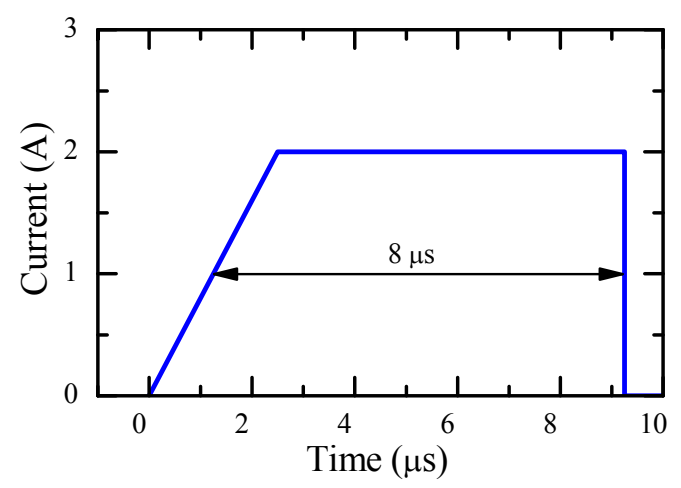

Figure 5. Modified pulse shape for increased tuning range.

Figure 6 shows a series of output spectra recorded with a FTIR using the new current pulses and a pulse frequency of $50 \mathrm{kHz}$. The tuning range was increased to $65 \mathrm{~cm}^{-1}$, representing a nearly $20 \%$ improvement 
over the previous results. Additional research is needed to determine the optimal pulse shape, which may depend on the particular QC device used.

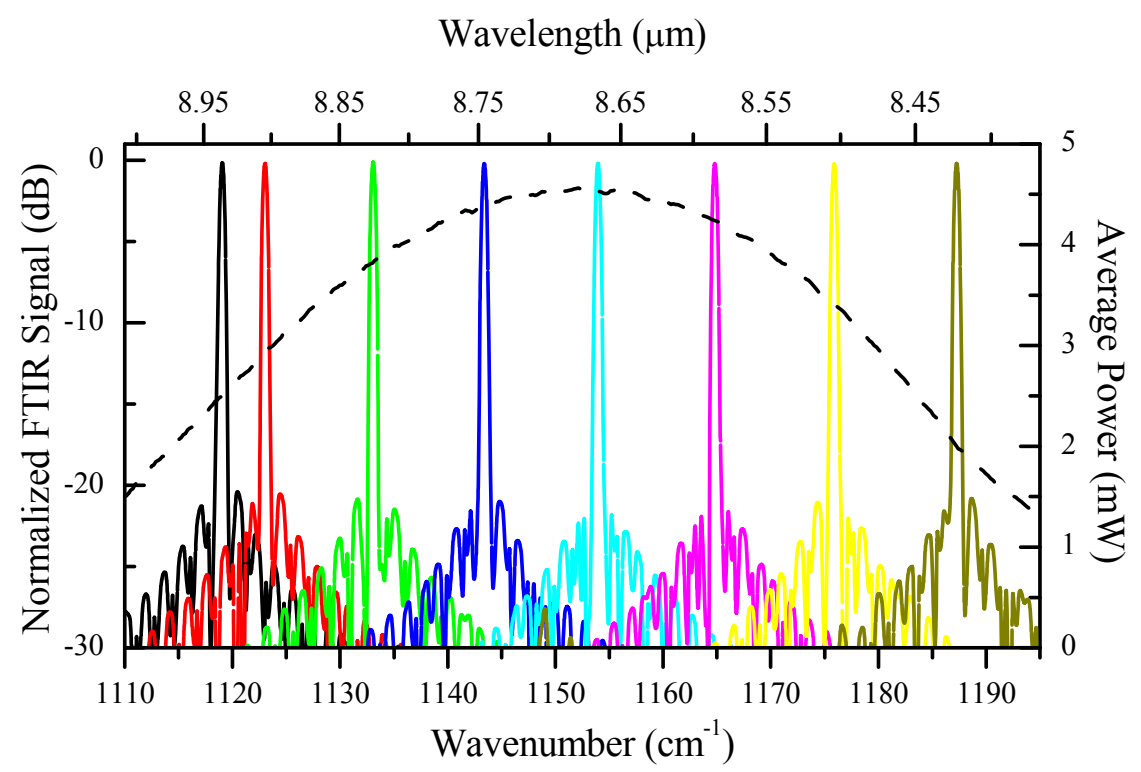

Figure 6. Increased tuning range of $8.7 \mu \mathrm{m}$ ECQCL with modified pulse shape. The solid lines show ECQCL output spectra recorded by the FTIR. The dashed line shows the average output power measured using a thermopile.

A second ECQCL system was constructed using a different QC laser device (FQ9-M532I) also obtained from Maxion Technologies. This QC laser was designed for room-temperature quasi-CW operation at a wavelength of $9.7 \mu \mathrm{m}$. In addition to providing a longer wavelength, this device offered the potential for higher power and CW operation due to growth and fabrication advancements made by Maxion. In particular, the device featured epi-layer down mounting and an AlN submount, a procedure which allows for better heat extraction from the laser active region. The laser device was AR-coated on the front facet and HR-coated on the back facet.

The performance of this laser was evaluated in the ECQCL system with parameters similar to those described above. The laser was held at $15^{\circ} \mathrm{C}$ by the thermoelectric cooler. The laser was operated at $50 \%$ duty cycle by applying pulses with $2 \mathrm{~A}$ peak current at a frequency of $10 \mathrm{kHz}$ and a pulse duration of 50 $\mu$ s. Figure 7 shows a series of ECQCL output spectra for different tuning mirror angles, recorded by the FTIR. This device provided a large tuning range of $987-1100 \mathrm{~cm}^{-1}(9.09-10.13 \mu \mathrm{m})$, spanning more than $110 \mathrm{~cm}^{-1}$. The dashed line in Fig. 7 shows the measured average output power, which was greater than 10 $\mathrm{mW}$ in the central portion of the tuning range. Unfortunately, before it could be used for a sensing demonstration the QC device failed during operation for an unknown cause. It was noted while the device was still operating that the output beam profile had imperfections, and it is possible that facet damage may have led to the device failure. Additional QC laser devices were acquired from the same wafer, and will be characterized and used in FY08. 


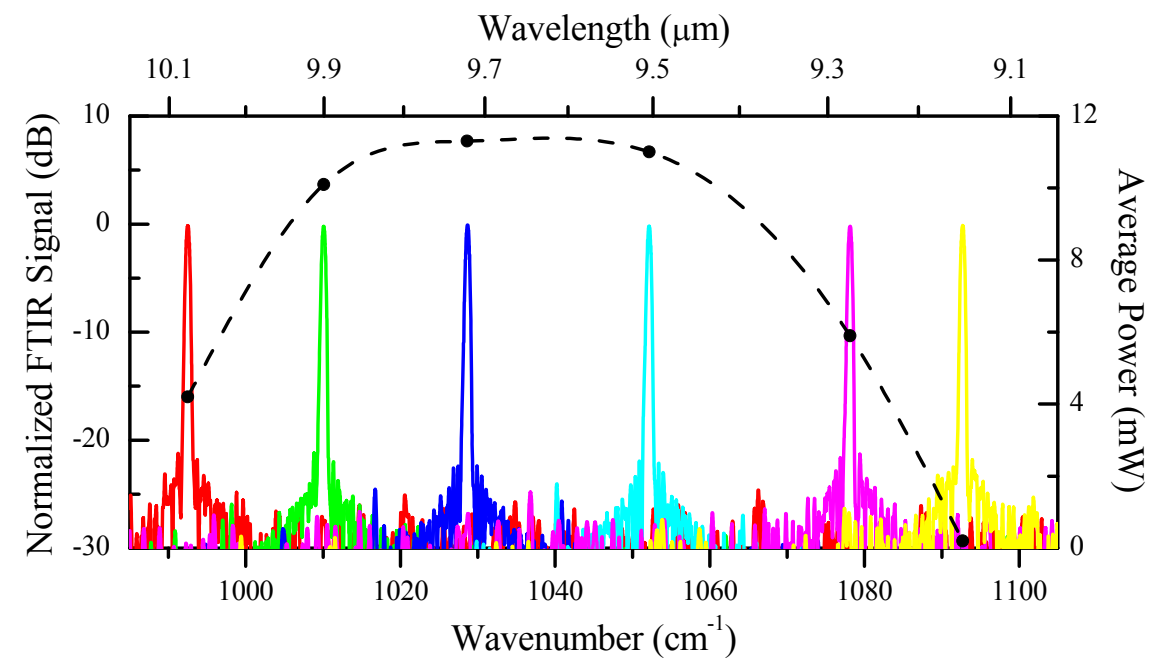

Figure 7. Characterization of ECQCL designed for operation at $9.7 \mu \mathrm{m}$. The solid lines show a series of ECQCL output spectra (solid lines) recorded using an FTIR spectrometer. The dashed line shows the average output power recorded using a thermopile.

\subsection{Photoacoustic Spectroscopy of Broad Absorption Features}

As part of the research effort this year, we evaluated the performance of the ECQCL for detecting molecules with broad absorption features using two different sensing techniques. The first technique was based on laser photoacoustic (LPAS) spectroscopy using quartz tuning fork (QTF) transducers. Figure 8 shows photographs of (a) the QTF transducer, and (b) the gas cell used for the sensor demonstration. Under a previous DARPA project, PNNL had developed infrastructure and experience in building sensors based on QTF transducers. While the DARPA project involved using fixed-wavelength QC lasers, it was a natural extension to demonstrate a sensor using an ECQCL. Under this NA-22 project, we published the first demonstration of a QTF sensor using an ECQCL in the peer-reviewed journal Optics Letters [3]. The details of the experiments can be found in the published paper; here, we present a brief summary of the results. 

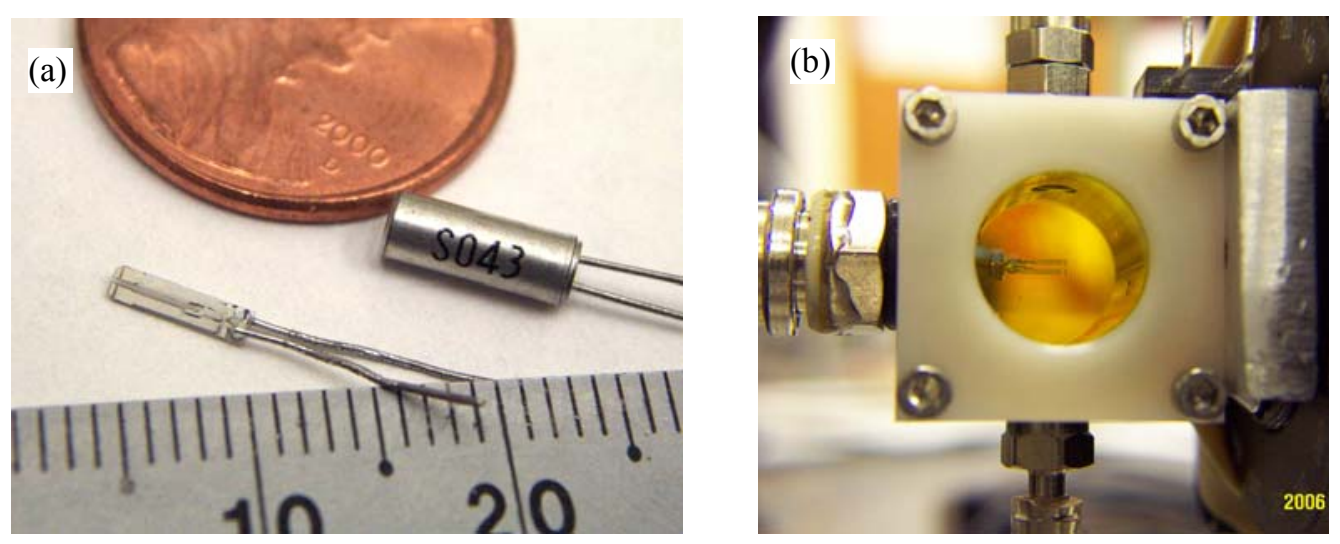

Figure 8. Photographs of quartz tuning forks (QTFs) used as photoacoustic transducers. (a) QTF transducers with and without cover. (b) A QTF mounted in a gas cell for spectroscopy measurements.

The ECQCL LPAS technique was used to demonstrate the measurement of broad absorption features. Figure 9 shows absorption spectra as measured using the ECQCL LPAS technique for Freon-125 (pentafluoroethane) and Freon-134a (1,1,1,2-tetrafluoroethane), each at a concentration of $10 \mathrm{ppm}$ and at atmospheric pressure. The dashed lines show reference absorption spectra from the Northwest Infrared (NWIR) spectral library [4]. As can be seen from the figure, the accuracy of the measurement was excellent, both in amplitude and frequency. The ECQCL system was able to resolve the characteristic spectral features of both molecules and easily distinguish the two molecules. From the measured signal amplitudes and noise, we determined the noise equivalent absorption coefficient (NEA) to be $4 \times 10^{-6} \mathrm{~cm}^{-1}$ obtained in a scan time of $250 \mathrm{~s}$. Using an effective noise bandwidth of $0.31 \mathrm{~Hz}$ calculated from the lockin amplifier time constant, the power normalized sensitivity $\mathrm{D}$ had an average value of $3 \times 10^{-8} \mathrm{Wcm}^{-1} \mathrm{~Hz}^{-1 / 2}$ over the ECQCL scan.

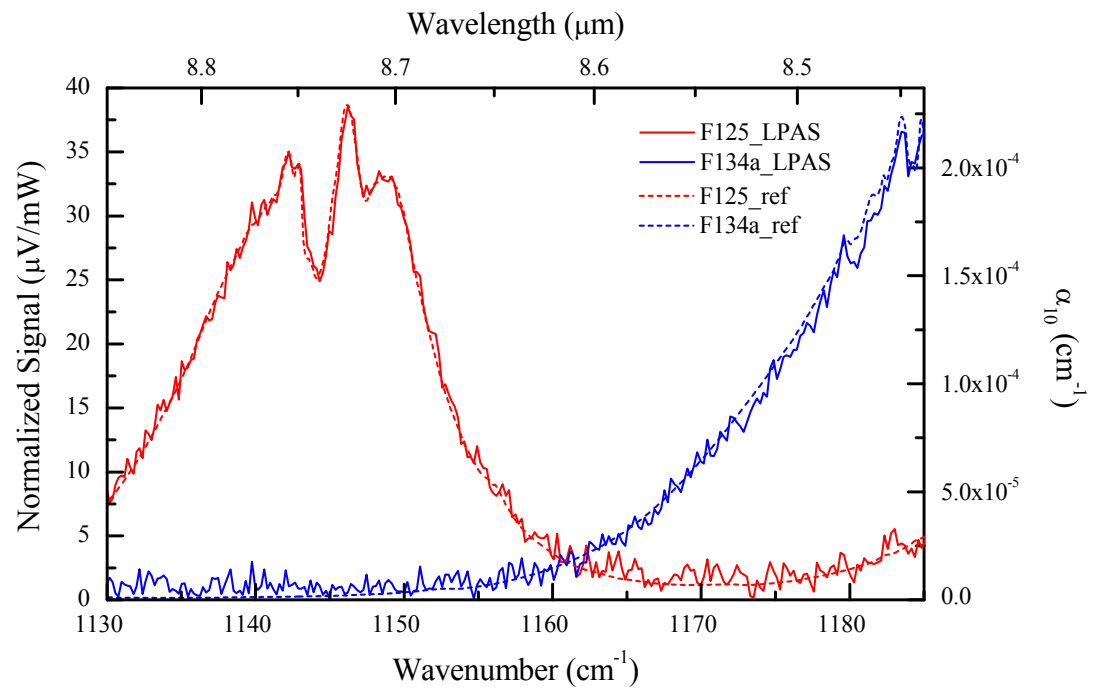

Figure 9. Measurement of broad absorption features using QTF photoacoustic spectroscopy. The solid lines show the measured photoacoustic signals for Freon-125 (red) and Freon-134a (blue). The dashed lines show spectra from the NWIR library. 
From our results, we determined that the LPAS technique represents a useful sensor architecture when combined with the ECQCL for measurement of molecules with broad absorption features. Although the sensitivity is not as high as for the Herriott cell measurements described in Section 4 below, it has the advantage of a small sensor size and correspondingly small gas volume required for sampling. The QTF transducers are inexpensive and readily available electronic components. In addition, the QTF sensor does not require cryogenic cooling in contrast to high-sensitivity MCT infrared optical detectors. The LPAS sensitivity could be increased further by using higher laser power (because it is a photoacoustic technique, the signal scales with laser power); however, it would be difficult to match the sensitivity of the Herriott cell technique. The LPAS technique therefore represents a good solution for a compact sensor system which does not require the higher sensitivity provided by the Herriott Cell.

\subsection{Herriott Cell Spectroscopy of Broad Absorption Features}

The second sensing technique investigated this year for measurement of broad absorption features using the ECQCL was to use a Herriott cell long-path length cell. These measurements were highly successful and were documented in the report entitled Long Wave Infrared Detection of Chemical Weapons Simulants [5]. Additionally, the results were presented at the 2007 SPIE Optics East Conference and published in the conference proceedings [6]. A brief summary of the results is presented here.

The Herriott cell sensor utilizes two curved mirrors to create a long path length for increased absorption, while keeping the footprint reasonable. For our experiments with the ECQCL, we used a Herriott cell constructed from $15 \mathrm{~cm}$ diameter mirrors placed $22 \mathrm{~cm}$ apart, and configured for a total path length of $47 \mathrm{~m}$, corresponding to approximately 209 passes of the cell. Figure 10 shows a photograph of the Herriott cell.

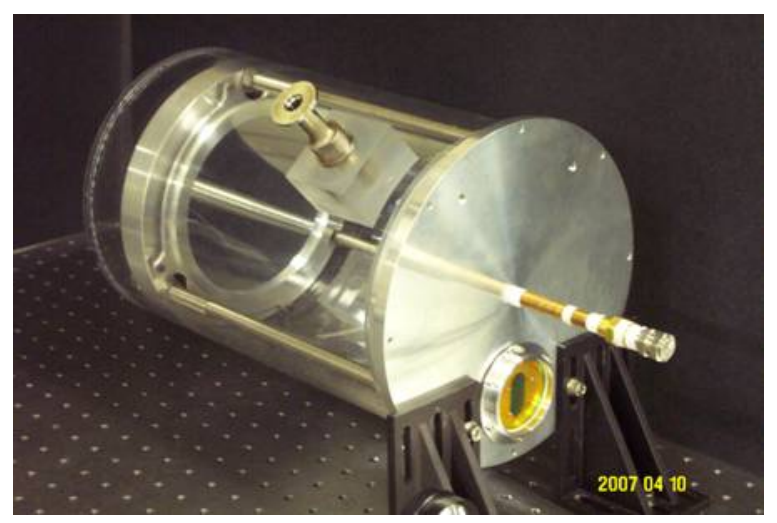

Figure 10. Photograph of Herriott cell.

Using the ECQCL, we measured the absorption spectrum of Freon-125, at a concentration of $10 \mathrm{ppm}$ and at atmospheric pressure. Figure 11 shows an experimental absorption spectrum obtained using the ECQCL and Herriott cell, as well as the reference absorption spectrum from the NWIR spectral library. The agreement between the data was excellent, and the spectra were nearly indistinguishable. We determined the NEA to be in the range of $0.5 \times 10^{-7}$ to $1 \times 10^{-6} \mathrm{~cm}^{-1}$ for scan times as short as $40 \mathrm{~s}$. 


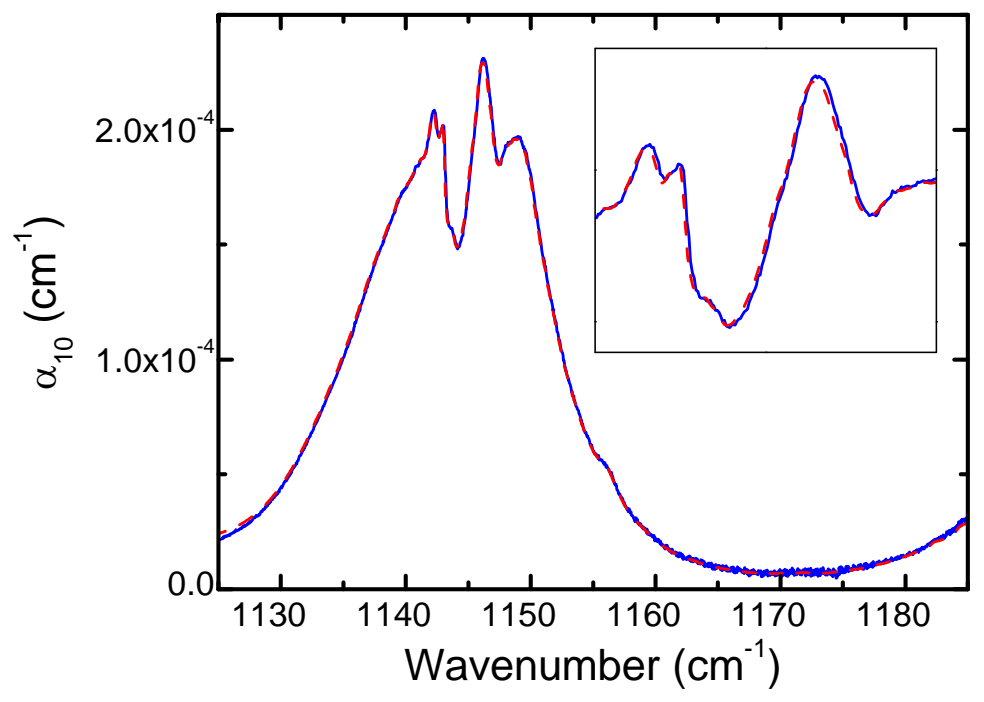

Figure 11. Measurement of Freon-125 absorption spectrum using ECQCL and Herriott cell. The solid line is the experimental spectrum and the dashed line is the reference spectrum from the NWIR spectral library. The inset shows an expanded region at the absorption peak.

We also measured the absorption spectrum of water vapor present in the laboratory air, which has narrower absorption features. Figure 12 shows both the (a) experimental absorption spectrum and (b) the NWIR reference spectrum. Again, the agreement between the spectra was excellent. This measurement also demonstrates that the ECQCL has sufficiently high resolution to resolve the narrow absorption features of atmospherically broadened simple molecules. These pressure-broadened absorption lines are typically no narrower than $0.1 \mathrm{~cm}^{-1}$ and the $0.14 \mathrm{~cm}^{-1}$ scan resolution of the ECQCL system is able to resolve these features with minimal instrumental broadening. Therefore, the ECQCL with the configuration described here is capable of detecting the absorption spectra of both simple and complex molecules at atmospheric pressure. 


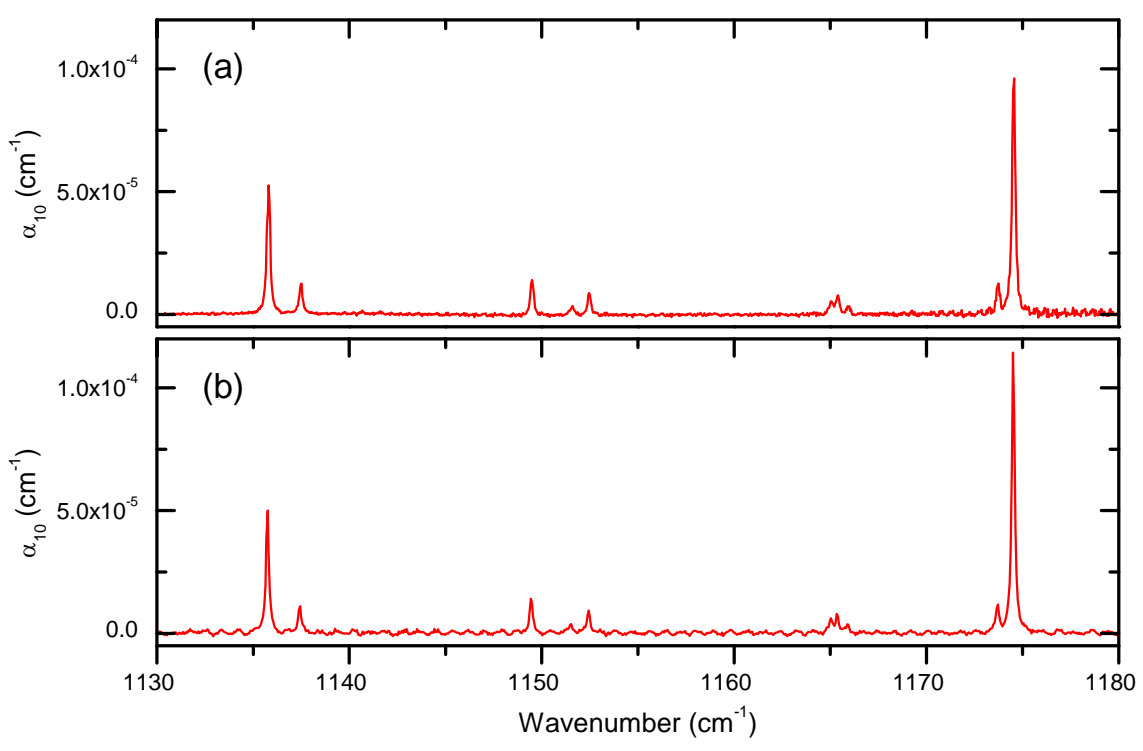

Figure 12. Measurement of water vapor absorption spectrum using ECQCL and Herriott cell. (a) Experimental spectrum and (b) reference spectrum from the NWIR spectral library.

Using the Herriott cell sensor, we were able to perform high-sensitivity gas measurements using the ECQCL. This sensor architecture offered higher sensitivity than the LPAS technique, but at the expense of a larger sensor system. The Herriott cell we used in the experiments presented here was not fully optimized for size and could be made more compact by using smaller diameter mirrors. While the experiments described here used a liquid nitrogen cooled MCT detector, its high sensitivity was not required for the measurements and in fact the laser had to be highly attenuated to avoid detector saturation. A TE-cooled MCZT detector should provide high enough detection sensitivity and also allow the system to be made completely cryogen-free.

\subsection{Final Remarks}

Two ECQCL systems were constructed and characterized this year, designed for broad tuning applications. The first system operated near $8.7 \mu \mathrm{m}$, and had a tuning range of up to $65 \mathrm{~cm}^{-1}$, with an average output power up to $5 \mathrm{~mW}$. The second system operated near $9.7 \mu \mathrm{m}$, and had a tuning range of $110 \mathrm{~cm}^{-1}$, with an average power greater than $10 \mathrm{~mW}$. The ECQCL system at $8.7 \mu \mathrm{m}$ was used for spectroscopy of broad absorption features using two sensing techniques: photoacoustic spectroscopy using QTF transducers, and Herriott cell spectroscopy. The LPAS technique had the advantage of small size, but was not as sensitive as the Herriott cell technique.

The results obtained this year have demonstrated that the ECQCL system can measure the absorption spectra of complex molecules with broad absorption features. This capability opens up significant opportunities for gas-phase chemical sensing, and greatly expands the number of analytes which can be sensed. In addition, the ECQCL system was able to resolve the atmospherically broadened absorption 
lines of simple molecules. Although the ECQCL system will probably not be able to match the sensitivity of a DFB-based system using $2 \mathrm{f}$ detection, this limitation is compensated by its versatility. The two types of QC laser systems should be viewed as complementary, and their use based on the particular application.

The ECQCL laser was designed to scan without compensating for EC mode-hops. Furthermore, the QC laser was operated in pulsed mode at a high duty cycle. While both of these factors acted to increase the effective linewidth of the ECQCL, we found that the scan resolution was sufficient to measure the spectral features of interest. The advantages to this mode of operation included a simpler engineering of the ECQCL cavity, and increased laser performance running pulsed instead of CW. The pulsed operation was effectively used with lock-in detection to reduce noise and increase the sensitivity for both sensing techniques investigated.

In FY2008, we plan to include the ECQCL in a sensor platform for field deployment, and use it to measure a chemical with broad absorption features. For maximum sensitivity, the sensor will use a Herriott cell spectrometer. Modifications to the ECQCL design will be required to make it rugged for field deployment, and the drive electronics will need to be reduced in size and power consumption. We also plan to increase the scan speed of the ECQCL to enable investigation of the rapidly changing gas concentrations expected during a field deployment.

\subsection{References}

1. R. Maulini, A. Mohan, M. Giovannini, J. Faist, and E. Gini, "External cavity quantum-cascade laser tunable from 8.2 to 10.4 mu m using a gain element with a heterogeneous cascade," Appl. Phys. Lett. 88, 201113 (2006).

2. M. G. Littman and H. J. Metcalf, "Spectrally Narrow Pulsed Dye-Laser without Beam Expander," Appl. Opt. 17, 2224-2227 (1978).

3. M. C. Phillips, T. L. Myers, M. D. Wojcik, and B. D. Cannon, "External cavity quantum cascade laser for quartz tuning fork photoacoustic spectroscopy of broad absorption features," Opt. Lett. 32, 1177 (2007).

4. S. W. Sharpe, T. J. Johnson, R. L. Sams, P. M. Chu, G. C. Rhoderick, and P. A. Johnson, "Gasphase databases for quantitative infrared spectroscopy," Appl. Spectrosc. 58, 1452-1461 (2004).

5. M. C. Phillips, M. S. Taubman, D. C. Scott, T. L. Myers, J. T. Munley, and B. D. Cannon, "Long Wave Infrared Detection of Chemical Weapons Simulants," PNNL-16557 (Pacific Northwest National Laboratory, Richland, Washington, 2007).

6. M. C. Phillips, T. L. Myers, M. D. Wojcik, B. D. Cannon, M. S. Taubman, and D. C. Scott, "Measurement of broad absorption features using a tunable external cavity quantum cascade laser," in Infrared, Mid-IR, and Terahertz Technologies for Health and the Environment II, (SPIE, 2007), 676003-676011. 


\section{Distribution}

No. of

Copies

OFFSITE

Dr. Victoria Franques

United States DOE

NNSA/NA-22

1000 Independence Ave. SW

Washington, DC 20585
No. of

Copies

ONSITE

9 Pacific Northwest National Laboratory

Bruckner-Lea, C K5-25

Clemmer, RG K8-02

Myers, TL (2) K5-25

Phillips, MC K5-25

Sharpe, SW K8-88

Taubman, MS K5-25

Information Release Office (2) K1-06 


\section{Email notification only}

\section{OFFSITE}

Dr. Rhys M. Williams

United States DOE

NNSA/NA-22

1000 Independence Ave. SW

Washington, DC 20585

Dr. David Berry

United States DOE

NNSA/NA-22

1000 Independence Ave. SW

Washington, DC 20585

Mr. Ralph Hastings

United States DOE

NNSA/NA-22

1000 Independence Ave. SW

Washington, DC 20585

Mr. Eric Sander

United States DOE

NNSA/NA-22

1000 Independence Ave. SW

Washington, DC 20585

Mr. W. Randy Bell

United States DOE

NNSA/NA-22

1000 Independence Ave. SW

Washington, DC 20585 